\title{
TRAMA DE VINCULACIONES PERSONALES Y PROFESIONALES DESDE LA VOZ DEL PROFESOR
}

\section{PLOT OF PERSONAL AND PROFESSIONAL CONNECTIONS FROM THE TEACHER'S VOICE}

\author{
María Luisa García Martel ${ }^{1}$ - Ilda Avelina Mieres ${ }^{2}$
}

Fecha de recepción: 28-09-2019

Fecha de aceptación y versión final: 02-06-2020

\section{Resumen}

Este artículo se configura en torno a una indagación respecto del currículum vitae de una docente y al análisis del mismo desde la perspectiva relacionada con la noción de currículum como espacio de formación disciplinaria. Cobró sentido en este trabajo la idea de significatividad, entendida ésta como principio subyacente de selección que explica las elecciones, actitudes, decisiones y adhesiones que el individuo expresa y realiza, en este caso particular en relación con la vida profesional.

El enfoque cualitativo fue el pilar metodológico de este trabajo ya que se buscó comprender una situación particular, contextualizada en un tiempo histórico determinado. Por ello se revalorizó la perspectiva de los actores involucrados.

Las conclusiones giran, en principio, en torno a la posibilidad de describir el trayecto profesional de un docente, mostrando diferentes actividades de una persona en un ordenamiento espacial y temporal determinado. Se pueden identificar períodos o etapas en diferentes niveles y funciones y se advierten, además, períodos de aceleramiento y condensación de actividades que hace pensar en una intensificación laboral. Asimismo, se identifican segmentos temporales en los que el camino se presenta pautado, lento, sereno, por tramas particulares de la vida personal. Vale la pena destacar la importancia ejercida por las presiones políticas y sociales en tiempos de ocupar cargos jerárquicos, siendo detonantes de renuncias en el desempeño profesional. La cuestión de la significatividad puso en el centro de la escena el entramado singular de la esfera personal con la esfera profesional.

Palabras clave: trayecto profesional- currículum vitae- significatividad

\section{Abstract}

This article is based on an inquiry about the curriculum vitae of a teacher and the analysis of it from the perspective related to the notion of curriculum as a space for disciplinary training. It made sense in this work the idea of significance, understood as the underlying principle of selection that explains the choices, attitudes, decisions and adhesions that the individual expresses and performs, in this particular case in relation to professional life.

\footnotetext{
${ }^{1}$ Profesora y Licenciada en Ciencias de la Educación. Especialista en Docencia Universitaria, Especialista en Didáctica y Currículum. Doctoranda en Ciencias de la Educación. Profesora Titular Regular de Investigación en Educación Inicial y Taller de Integración, Investigación y Práctica II del Profesorado y Licenciatura en Educación Inicial de la facultad de Humanidades, UNNE. Domicilio: Pasaje Arturo Lestani 1453. Resistencia, Chaco - República Argentina. Correo electrónico: ml.garciamartel@ gmail.com ${ }^{2}$ Profesora en Ciencias de la. Educación. Especialista en Didáctica y Curriculum. Profesora en el Instituto de Nivel Superior San Fernando Rey en cátedras del campo general y del sujeto. Domicilio: Larreta y Pasaje Vedia, Resistencia, Chaco - República Argentina. Correo electrónico: ildaam06@yahoo.com.ar
} 
The qualitative approach was the methodological pillar of this work, since the aim was to understand a particular situation, contextualized in a certain historical time. Consequently, the perspective of the actors involved was revalued.

In principle, the conclusions revolve around the possibility of describing the professional path of a teacher, showing different activities of a person in a specific spatial and temporal order. There are periods or stages at different levels and functions and there are also periods of acceleration and condensation of activities that suggest labor intensification. Likewise, there are temporary segments in which the trail is ruled, slow, serene, due to particular circumstances of personal life. It is worth stressing the importance exerted by the political and social pressures in times of occupying hierarchical positions, being the triggers of resignations in the professional performance. The question of significance put on the center stage the close relationship between the personal sphere and the professional sphere.

Key words: Professional path- Curriculum vitae- Significance

\section{Introducción}

Este trabajo se configura en torno a la aproximación a un currículum vitae de una colega docente y al análisis del mismo desde la perspectiva relacionada con la noción de currículum como espacio de formación disciplinaria. Cobraron sentido en este trabajo algunos conceptos de Schutz (1973), en particular la idea de significatividad, entendida ésta como principio subyacente de selección que explica las elecciones, actitudes, decisiones y adhesiones que el individuo expresa y realiza, en este caso particular en relación con la vida profesional. Como expresa el autor, un sujeto decide un curso de acción en un sentido y no en otro a la luz de lo que considera significativo con respecto a sus más profundas convicciones e intereses. importante:

En este contexto particular de análisis de un curriculum vitae, resulta entonces

$>$ Describir el trayecto profesional de un docente, a partir de las cuestiones que surgen del análisis mismo del currículo vitae.

$>$ Interpretar el recorrido realizado, las decisiones tomadas y alternativas vislumbradas, considerando la voz del docente.

$>$ Conocer las condiciones y los supuestos que inciden en la trayectoria profesional.

En el marco de estos propósitos algunas preguntas de exploración ayudaron a restringir la mirada y el análisis: ¿Qué actividades realizó este docente? ¿Qué diferencias hay en la estructura de actividades que realizó, si es que hay alguna? ¿Pueden reconocerse periodos de condensación de actividades que hace pensar en una intensificación laboral o, por el contrario, el camino se presenta lento y orientado en una sola dirección? ¿Qué significado tiene estas señales? ¿La vida profesional constituye algo separado de la vida corriente de una persona? ¿Cómo opera el contexto socio histórico político en las trayectorias?

Al respecto y dentro del marco de las ideas trabajadas por el autor nombrado, cada sujeto integra un mundo de cotidianeidad; "el mundo cotidiano de la acción es el presupuesto que, como bucle recursivo, entrama todos los demás estratos de la 
realidad humana" (García de Ceretto, 2007, p. 45). El rasgo fundamental de la acción es el hecho de ser proyectado y estar dotado de propósito.

Desde esta perspectiva, resulta relevante abordar la trayectoria profesional vinculada al ciclo vital de una persona, al curso de acción que cada sujeto emprende configurando así su recorrido profesional, situándose en la vida de una manera específica a la luz de su situación biográfica. En este sentido la vida profesional y la historia personal se articulan y se imbrican en el marco de una trama social y política que marca huellas e incide en decisiones en contextos de significación.

En relación con el contexto del sistema educativo argentino y las demandas actuales, en la década del '90, surgieron necesidades relacionadas con la formación de grado, posgrado y la capacitación docente. Tales demandas llegaron a ser condicionantes en la vida profesional y por ello cobran un papel central en los desarrollos de las trayectorias, cuestión que se aborda en este artículo.

Tener un título de grado para conservar la fuente de trabajo, realizar carreras de postgrado para lograr mejor posicionamiento profesional y posibilidades de acceder a otros puestos de trabajo, como así también la encrucijada de inscribirse y concretar cursos de capacitación pertenecientes a programas provinciales de única oferta, fueron cuestiones vividas como impuestas y a la vez movilizadoras en cuanto a la necesidad de permanencia y estabilidad en el sistema, requisitos que desde el análisis socio político no se pueden evadir en este trabajo.

Entre las condiciones que delimitan la vida, se pueden identificar dos tipos de elementos según Schutz (1973): los que controlo o puedo llegar a controlar, y los que están fuera o más allá de mi posibilidad de control. Es importante comprender cómo se nos da este mundo de la vida cotidiana. La realidad del sentido común nos es dada en formas culturales e históricas de validez universal, pero el modo en que estas formas se expresan en una vida intelectual depende de la totalidad de la experiencia que una persona construye en el curso de la existencia concreta. Este autor afirma que, actuando en el mundo, las personas procuramos cambiarlo y alterarlo, modificar el escenario de nuestras actividades. Nuestra situación biográfica define el modo de ubicar el escenario de la acción, interpretar sus posibilidades y enfrentar sus desafíos. Incluso en la determinación de lo que el individuo puede o no modificar influye su situación exclusiva. La experiencia fundamentada de una vida condiciona la subsiguiente interpretación de todo nuevo suceso y actividad. Es aquí donde se pone en juego la situación biográfica y el acervo de conocimientos.

Por tanto, "la situación actual del actor tiene su historia; es la sedimentación de todas sus experiencias subjetivas previas, que no son experimentadas por el actor como anónimas, sino como exclusiva y subjetivamente dadas a él y sólo a él" (Natanson, 1974, p.17).

Estas definiciones se condicen con el sentido de experiencia que plantea Larrosa (2014) "es eso que me pasa. No eso que pasa, sino eso que 'me' pasa" (p.14) Este autor plantea que "el lugar de la experiencia soy yo. Es en mí (...) donde se da la experiencia, donde la experiencia tiene lugar" (p.16).

Es sabido que un soporte papel muchas veces burocrático no alcanza para comprender los recorridos profesionales, las experiencias, aunque en sí mismo el currículum vitae "narre" los tramos transcurridos. Por ello, en este momento cobra 
cabal sentido el uso de entrevistas, en tanto narrativa del propio recorrido profesional, en tanto "la voz" de los actores involucrados que emerge e interpela.

En este sentido ambos elementos, documental e intercambio oral, aportan datos para producir conocimiento relevante respecto de la trayectoria docente particularmente, acerca de las atribuciones de sentido, el por qué y el para qué de las elecciones, lo que da cuenta de interrupciones, continuidades, disonancias, a partir de una estructura formal -el currículum vitae- y desde la dinámica particular de la trayectoria expresada por el docente.

\section{Descripción Metodológica}

Desde una perspectiva interpretativa se reconoce que la realidad social no es algo hecho o dado, fijo y estable, sino que se trata de una realidad cambiante e inacabada, en proceso de construcción, constituida por un entramado de elementos objetivos y subjetivos. Cuando se aborda la realidad social desde esta mirada, se intenta describir las características observables, de un acontecimiento, así como también se trata de conocer la interpretación que le conceden los participantes. Por lo tanto, además de conocer el contexto real, se hace necesario conocer lo que perciben y sienten los implicados, para comprender la interrelación de ambas.

En este artículo se considera un caso, que implica describir una trayectoria docente a partir de un documento escrito, el currículum vitae, pero se complementa esta indagación con la voz del protagonista, quien expresó previamente su recorrido profesional en un papel siguiendo aspectos formales.

El enfoque cualitativo es el pilar metodológico de este trabajo ya que se busca comprender una situación particular, contextualizada en un tiempo histórico determinado, Por ello se revaloriza la perspectiva de los actores involucrados, teniendo presente "ser más fiel al fenómeno que se estudia que a un conjunto de principios metodológicos" (Gallart, 1992, p.115). Esta es la razón por la cual se siguen -en esta metodología- algunos lineamientos orientadores, pero no estrictas técnicas y reglas metodológicas.

A partir de los interrogantes iniciales de exploración del caso, se intenta descubrir categorías para el análisis:

I- Cuestiones vinculadas al título profesional.

- interrupciones.

- cambios con inicio de otra actividad.

- carencia de inicios. vacío de actividad.

- continuidades.

- orientaciones que se privilegian.

II- Cuestiones no vinculadas al título profesional.

Estas categorías se fueron descubriendo a partir de comparaciones y asociaciones necesarias que llevaron a identificar información relevante y a dar nombre a aspectos que emergen desde un primer momento de exploración y análisis 
de datos. La comparación continua de incidentes específicos aportados por los datos nos indica la presencia de una metodología de análisis según una estrategia de método comparativo constante.

Como fuente de datos inicial se utilizó el Currículum vitae tal como se presenta a llamados de antecedentes o concursos. Estas primeras letras dieron pie para ir construyendo instrumentos de sistematización y análisis, que se iniciaron a partir de borradores de líneas temporales para finalizar en una matriz de doble entrada, cuya columna organizadora son "las actividades" realizadas e indicadas en el currículum y desde las coordenadas horizontales se presenta en que tiempo se dieron, tomando como parámetro períodos anuales, desde la fecha de la primera actividad presentada. El instrumento permite también fraccionar los tiempos por semestres.

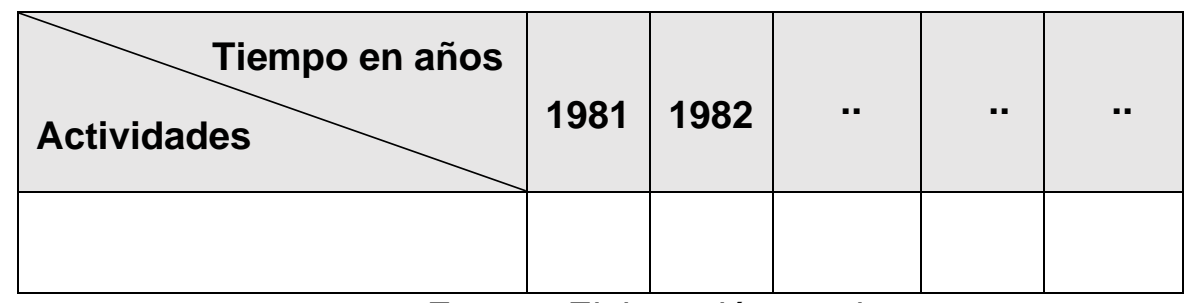

Fuente: Elaboración propia.

Vale reconocer que este instrumento resultó de mucho valor a la hora de identificar información relevante, pero asimismo resultó de difícil manejo por las dimensiones que alcanzó a cobrar. Un modo de simplificarlo sin reducir información relevante es codificando las actividades con número de orden, produciendo una reducción en esa columna, en cuanto a su extensión en renglones y en cuanto a su ancho.

Por otro lado, otro instrumento central de recolección de datos fue la entrevista en profundidad. Al respecto se elaboraron preguntas vinculadas al primer análisis y a las categorías encontradas. El tipo de preguntas se caracteriza por ser abiertas, no estructuradas, evitando dar posibles respuestas y permitiendo responder libremente sobre la base de marco de referencia: ¿Puede revisar su trayectoria profesional en diferentes momentos? ¿Cree que hubo continuidad en algunos aspectos? Aparecen años con menor grado de actividad, ¿puede explicarlo?

Para analizar la información de las entrevistas se procedió a sistematizarla también en una matriz que destaca los siguientes aspectos:

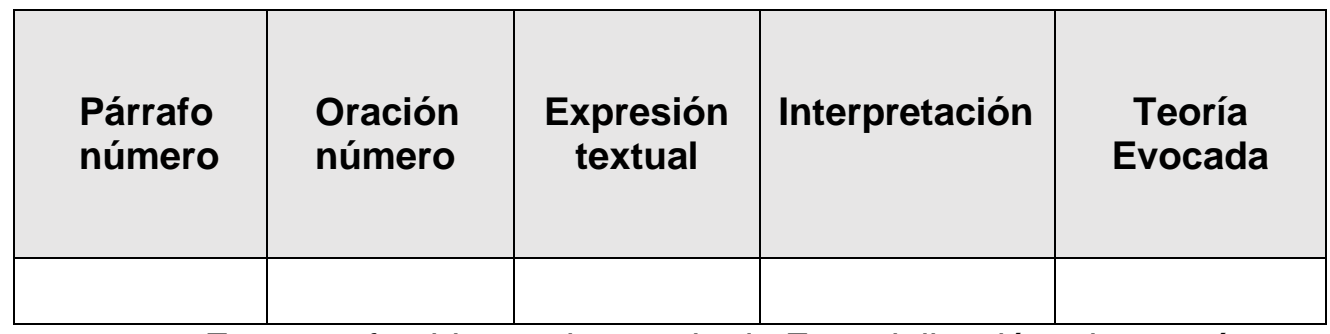

Fuente: ofrecido en el cursado de Especialización, sin autoría. 
En cuanto al análisis se procedió desde un enfoque orientado hacia el desarrollo de una comprensión en profundidad de los escenarios o personas que se estudian. Las comprensiones están fundamentadas en los datos y se desarrollan a partir de ellos.

\section{Análisis}

Del análisis documental y de la entrevista se recuperan elementos centrales que se organizan en la siguiente síntesis:

Decisiones relacionadas con el ordenamiento social - espacial.

- Motivos vinculados a la elección de la carrera y a la diversidad de actividades en la función docente: influencia de terceros.

- Motivos vinculados al contexto en general socio político cultural.

- Motivos vinculados al ámbito familiar.

Decisiones relacionadas con el ordenamiento temporal- espacial.

- Movimientos: ritmos y direcciones.

\section{En cuanto al ordenamiento social- espacial}

En primer lugar, se presentan las decisiones personales inducidas por estimulación por "terceros" dado que este tipo de motivaciones se observa repetidas veces en la entrevista, razón por la cual consideramos importante darle un lugar en la apertura de esta presentación.

Analizar un currículo vitae entendido en su significado más literal como "carrera vital", es decir, como "aquello que hemos vivido", realmente resultaría imposible, dice Salinas (1995), si nos quedáramos con el documento escrito: El autor afirma que:

El documento que, en momentos determinados, presentamos bajo el título de "currículum vitae" y que comienza por nuestros nombres y apellido, y datos administrativos, sólo representa una mínima parte de lo vivido. Probablemente, ni siquiera lo más significativo de nuestra vida aparece en ese documento [...]

Nuestra vida cotidiana es más compleja, desorganizada, imprevisible, que lo presentado en el documento escrito con sus corrientes justificaciones documentales. El documento refleja una parte de lo que acontece en esa vida. (p.31).

Retomando la idea de la complejidad de la vida resulta necesario remitirnos a la situación biográfica de las personas dado que ésta define el modo de ubicar el escenario de la acción, interpretar sus posibilidades y enfrentar sus desafíos. Incluso en la determinación de lo que el individuo puede o no modificar influye su situación exclusiva.

En este sentido, en la definición del escenario de la acción entran en juego las decisiones personales. Si bien éstas son personales, para el caso particular de análisis, algunas situaciones de la vida cotidiana "se le vuelven" significativas a partir de estimulaciones de "terceros". Las motivaciones tienen un origen "exterior" a la persona involucrada en el caso: tienen unos "otros", pertenecientes a su contexto de interacción social inmediato, que condicionan su accionar. 
Esto se evidencia en diferentes momentos, desde la elección por la carrera hasta decisiones respecto de la diversificación de tareas emprendidas como docente y más aún, de la inserción en nuevos ámbitos profesionales. Para destacar la elección de la carrera recuperamos la pregunta inicial de la entrevista: "cuéntame acerca de las decisiones para empezar esta carrera". La respuesta inmediata fue: "si yo te cuento morís de un infarto... ¿te cuento?” Esta última expresión: “¿te cuento?” se presenta como un indicador de lo insólito de la respuesta, pareciera aún que es insólito para ella misma. Seguidamente dice "y apareció una amiga... me hizo un hermoso pantallazo de lo que era la ciencia de la educación, y yo me entusiasmé mucho, dije: está buena la idea, está buena la educación. Yo en mi vida había visto algo de filosofía, de psicología, así que... se imaginan..." (luego, expresa que es perito mercantil).

Evidentemente esta alternativa no se vislumbraba en su proyecto personal, y la circunstancia de que "apareció una amiga" fue un factor detonante de otras proyecciones.

En el transcurso de la entrevista se pueden apreciar varias opciones realizadas por "invitación de terceras personas". Las expresiones "me dijeron: hacé un coro..."; "¿sabés como trabajé en pintura...? una de las chicas me dice: querés venir a dar clases..."; "me invitan a adscribirme a la facultad..." ; "querés participar en la organización de las jornadas...?"; "me invitaron como expositora del primer curso de..." , todas dan cuenta que las decisiones se vinculan con cierto ordenamiento social, esto revela que si bien el sujeto define el mundo desde su propia perspectiva 0 subjetividad, sedimentada y estructurada de manera exclusiva, es un ser social que pertenece a una realidad intersubjetiva. La intersubjetividad, clave de la realidad social, dice Schutz, se la presupone como una cualidad obvia de este mundo. En este contexto los hombres definen su situación, y definir significa actuar y esto implica proyectarse.

Respecto de esta recurrencia en el análisis, y ante nuevos interrogantes realizados a la entrevistada, se destaca en principio la generación de ciertas condiciones para que surjan las invitaciones o sugerencias. El presente trabajo no busca ahondar en estas condiciones, pero si cabe señalar la frecuencia con la que ocurrieron, y, es más, fueron aceptadas.

La docente deja traslucir algunas probables razones de la aceptación de estas sugerencias de terceras personas. Hay una respuesta que se reitera y que refleja cierto reto a partir de lo novedoso o hasta ahora no incursionado. Ella afirma: "Y me gustó la idea", siempre acompañando esa expresión con una sonrisa y aparentemente entusiasmada. Cabe entonces preguntarse: ¿Podría sentirse estimulada ante los desafíos? ¿Podría dar seguridad y cierto "apoyo" el hecho de aceptar propuestas profesionales realizadas por terceros? Se considera pertinente dejar estos interrogantes abiertos dado que los datos recogidos no son suficientes para abordar en profundidad esta faceta de la cuestión.

Se afirma que, en este ordenamiento social, fluye la relación con los semejantes: los "alteregos", como expresa Schutz. El conocimiento del otro, el alterego, es posible "en un presente inmediato... lo captamos como un ahora, esta simultaneidad es la esencia de la intersubjetividad" (Natanson, 1974, p.21). Los otros semejantes pueden ser: predecesores, contemporáneos, asociados y sucesores. En el caso particular se pueden mencionar dos categorías de alteregos: contemporáneos y 
asociados (vinculados a alguna acción), que influyen en las decisiones tomadas actuando como movilizadores de las mismas.

Estas justificaciones vinculadas a terceros se presentan como explicaciones causales y retrospectivas, al decir de Schutz (1973), se explican con "razones porque", y refieren a dilucidar razones o factores que inciden en este caso en la dinámica de los procesos de toma de decisiones, o bien, parafraseando a Toulmin (1977) "el aspecto profesional (de una empresa racional) es causal, dilucidatorio y retrospectivo" (p.314).

La expresión inicial respecto de las situaciones que "se le vuelven significativas" remite al principio subyacente, principio de selección, que explica las elecciones, actitudes, decisiones y adhesiones que el individuo expresa y realiza. La "significatividad" es el rubro bajo el cual Schutz incluye los tipos y formas de acción emprendida por el individuo. Se decide un curso de acción en un sentido y no en otro, a la luz de lo que se considera significativo con respecto a mis más profundas convicciones e intereses, hay una especie de aquí y de ahora de la estructura de significatividades de la vida, un punto de origen ubicado en el centro mismo de la propia existencia axiológica, según el cual adquiere significación y dirección toda predicación evaluativa.

Este principio subyacente, la significatividad, puede ser temática, interpretativa y motivacional. En el caso particular se distingue la significatividad temática, como aquello que interesa, que se pone de relieve, que atrae la atención. Lo no familiar (la carrera profesional en educación) atrae la atención dentro de lo familiar circundante y encuentra un nuevo tema en el "salto" de un ámbito de realidad con estructura finita de sentido a otro, interrumpiendo un flujo de experiencia con su tema, "en mi vida había visto algo de filosofía, psicología", y encarando un nuevo tema, la opción por la formación docente. Paralelamente puede decirse que la atención estuvo "sugerida" socialmente, ya que las acciones de los semejantes plantearon temas que esta persona debió abordar. En virtud de esta significatividad los cursos y los resultados de los actos pueden ser totalmente inesperados, cuestión que es advertida por la entrevistada. "si te cuento morís de un infarto...".

Más allá de las decisiones tomadas por influencias de "terceros", hay otras que se fundan específicamente en "particulares intereses, motivos, deseos, aspiraciones, compromisos religiosos e ideológicos" (Natanson,1974, p.17). En este sentido, impactan algunas respuestas vinculadas a razones por las cuales se decide acerca de los ámbitos de estudio, cuestión que condiciona la trayectoria profesional de esta docente, en tanto que opta por una carrera de nivel superior, no universitario, en desmedro de la formación universitaria, con mayores proyecciones hacia el campo laboral. Resulta interesante al respecto recuperar las siguientes expresiones: "... encima me inscribí en el instituto porque no quería ir a la facultad, porque no me gustaba la facultad de humanidades por eso no me vine, y mi amiga que me conocía me dice: "te va a encantar (por el instituto de nivel terciario no universitario) porque es todo prolijito, limpito, ordenadito", y a mí los lugares donde está en desorden nunca me gustaron. Entonces me fui a estudiar a otro lado y no me viene a la universidad, aquí (haciendo alusión a esta ciudad; y se ríe...) qué loca que soy, y además lo que me gustaba era que había una formación religiosa, mal que mal, a mí me gustaba eso".

Puede notarse que la estructura de su personalidad incide en estas elecciones. Hay preferencias vinculadas al espacio, posiblemente en relación con espacios vividos y percibidos, al estado de un edificio, cuestiones vinculadas al decoro, ¿la apariencia?, 
el orden y la limpieza, la estética en general, que cobran fuerza en su destino profesional. Asimismo, una necesidad de contención espiritual la inclina por esa opción, institución de formación religiosa, como así también la supuesta seguridad que esas características institucionales (ideológicas y de forma) podrían ofrecerle. Se supone que se pone en evidencia cierta "inseguridad biográficamente condicionada con respecto a situaciones nuevas en general" (Schutz, 1973, p.191)

Los motivos "porque" que pueden explicar las decisiones, aparecen ocultos y marginales para la conciencia en este momento presente, pero en la reflexión acerca de un tiempo pasado, puede captarse como cierta toma conciencia acerca de esas razones. La evidencia se hace presente con las expresiones "qué loca que soy...", que nos indica que se dio cuenta de lo disparatada de la opción, y así también en la expresión evaluativa "mal que mal", dado que en esta última se hace un juicio de valor y se vislumbra entonces que la elección aparentemente no fue la mejor. Es sumamente probable que la misma narrativa generada por la entrevista, desde su función transformadora (Jackson, 2005), desde su potencial para "tomar conciencia", haya calado en este momento para ponerla de cara con sus propias decisiones y valorarlas desde un criterio un tanto arbitrario hoy, por qué no "de locura", agregando "que loca que soy... ¿eh?"; pero no obstante ese criterio habrá estado pleno de sentido, sin dudas, en aquél momento.

Asimismo, la opción de realizar una carrera de complementación para obtener título de grado universitario, ante la necesidad de acreditación de títulos en nuevas ofertas, denota que, entre varias alternativas, elige aquella que considera pertinente según su especial personalidad, su biografía personal, factores que inciden en la elección. Al respecto justifica la inscripción en una oferta académica universitaria de modalidad presencial, arancelada, ante ofertas estatales de modalidad semi presencial diciendo: "Yo soy un poco estructurada. Necesito mi seguimiento, mis clases... y por eso busqué (tal universidad...)". Se pone en evidencia nuevamente la necesidad de la presencia de otros, en un mismo espacio, cara a cara. Esta particular relación 'cara a cara' es fundamental para todas las demás estructuras de relacionabilidad social. En el encuentro cara a cara con asociados comparto una comunidad de espacio al alcance de ambos, en la cual interpreto los actos del otro, pero también una comunidad temporal. Los asociados toman parte en un fluir temporal continuo, demarcado por límites espaciales comunes. De tal modo, dice Natanson (1974) "cada copartícipe toma parte en el proceso vital del otro, puede captar en un presente vívido los pensamientos del otro a medida que son construidos paso a paso" (p.21). Para el caso, entonces, se puede sostener que las relaciones de contemporaneidad no son suficientes, en el sentido que no requieren conocer al otro y que el otro reconozca, simplemente necesitan compartir una realidad temporal pero no espacial.

Por otra parte, es importante considerar las condiciones contextuales que operaron en momentos decisivos de la trayectoria profesional. Al respecto, la entrevistada expresa "ay... me estaba acordando... porque quise hacer una especialización en desarrollo social en... (Una Universidad), entonces empecé los módulos y cuando empecé me dijo NN... (Que era la secretaria): "Mirá, para tener el título de la maestría vas a tener que tener el título universitario..." (El destacado es personal) y justo ahí aparecen las ofertas de la XX (institución universitaria privada). "Entonces yo dije cómo me voy a meter en esto, no puedo y no tengo este título, así que ahí decidí hacer la licenciatura para poder hacer una maestría, sino, no me habilitaba para hacerla...en esa época no me habilitaba, por eso me decidí sí o sí a hacer lo otro" (el destacado es personal). 
Como puede apreciarse a partir de los datos empíricos, en relación con la vida profesional, se puede decir que hay situaciones que el individuo puede controlar y para lo cual hace uso de su experiencia sedimentada ( experiencias previas, rutinas, que funcionan como esquemas de referencia y que constituyen su acervo de conocimiento) y hay otras que están fuera de sus posibilidades de control: situaciones novedosas inesperadas y para lo cual, tiene que improvisar, extrapolar dado que la rutina se suspende, se vuelve problemática, cuando se presentan incongruencias en nuestras expectativas o cuando se presenta alguna novedad: lo inesperado transforma nuestra rutina de la vida cotidiana y la sedimentación de nuestra experiencia en conocimiento. Ante tales cuestiones, incongruencias, novedades inesperadas, exigencias del medio, hay siempre una necesidad de adaptarse a cada situación. No es ésta una adaptación pasiva, dado el papel activo del sujeto al intentar modificar el mundo en que vive, según la situación particular que le toca vivir y en la cual entre en juego su historia personal. Desde estas exigencias del medio, se decide el ingreso a la carrera universitaria.

La necesidad acomodarse al contexto socio-político cultural revela que las decisiones no tienen un carácter puramente subjetivo, sino que están condicionadas a las posibilidades y oportunidades que se le presentan al individuo y que tienen que ver con el momento histórico en que se encuentran las profesiones. En este sentido, Toulmin (1977) sostiene que estas adaptaciones se definen en términos ecológicos y contextuales.

Del mismo modo la dimensión de lo económico se hace presente al momento de decidir, enfatizándose así la complejidad del mundo de sentido común y la incidencia de una multiplicidad de factores en las razones para hacer opciones de vida y profesional. A tal efecto se puede aseverar que las situaciones externas se imponen en la toma de decisiones, y en relación con ello, se destacan las siguientes expresiones de la entrevistada: "y tenía que tener las 30 hs" (el destacado es personal). Para el caso puntual, el verbo tener, construido con el pronombre que y el infinitivo de otro verbo (coincidentemente también tener), expresa la importancia de la acción significada por el infinitivo, denota la precisión o determinación de hacer lo que el verbo significa. No hay escapatoria a la acción de necesitar y tener, es imprescindible poseer 30 horas de trabajo. Seguidamente la docente explica que los motivos son de índole económica... por necesidad... necesidad económica..."

Por otro lado, expresa "yo me siento más tranquila, me gusta más trabajar en... (otro lugar) pero por razones económicas no dejo terciario, pero si pudiera lo dejaría". Más allá de los modos de sentirse en un ámbito de trabajo profesional, hay cierta presión y condicionamiento económico que marca y condiciona la trayectoria profesional, optando por cargos en los cuales las funciones se desarrollan en un clima de "menor tranquilidad", pero mejor rentado.

Se reafirma entonces que el desarrollo histórico de una profesión responde a razones y causas de índole personal pero también contextual. En este análisis de lo contextual debe considerarse que existen, en toda profesión, mecanismos políticos conocidos, esto es, la presencia de partidos y grupos de presión que son escenario de una pugna constante, manifestando los mecanismos e instrumentos propios de la vida y la actividad políticas en general. En relación con esta presencia, se marcan las presiones en las siguientes narrativas: "eso es lo que no me gusta del nivel terciario, tenemos una norma y después viene el hijo de Fulano que fue a hablar con el gobernador, ah nooo (enfatizando), y vienen te llaman por teléfono y te dicen...Tiene 
que hacer tal cosa. Chau tu normativa, esto, nos pasó. $Y$ te sacan una resolución...Entonces esas son las cosas que a mí me indignan". Nuevamente, al decir de Schutz (1974), hay cosas que no pueden controlarse y que alteran los mecanismos "normales" de funcionamiento, y la rutina se vuelve problemática.

Por otro lado, la docente manifiesta: "la presión de los alumnos, la presión de allá arriba, y yo decía... a cuál le hago caso, pero yo digo... yo vivo y convivo en mi institución con mis colegas. No vivo con ellos (haciendo referencia a la clase política dominante), entonces todas esas cuestiones hay que poder manejarlas, las manejas, pero... no es fácil... y si, son cuestiones políticas, no es fácil". Entendemos que cuando la docente remarca "yo vivo y convivo en mi institución con mis colegas. No vivo con ellos...", está destacando los vínculos con los alteregos, asociados, con quienes comparte un espacio de vida, y en estos casos también presionan desde la proximidad física.

Es oportuno señalar, en acuerdo con Leite Méndez y Rivas Flores (2014) que "los contextos sociopolíticos por los que han transcurrido las trayectorias profesionales (...) han ido estableciendo características propias y modos particulares de vivir la profesión" (p.135).

Larrosa (2014) afirma:

el sujeto de la experiencia es como un territorio de paso, como una superficie de sensibilidad en la que algo pasa y en la "eso que me pasa", al pasar por mí o en mí, deja una huella, una marca, un rastro, una herida. De ahí que el sujeto de la experiencia no sea, en principio, un sujeto activo, un agente de su propia experiencia, sino un sujeto paciente, pasional. $O$, dicho de otro modo, la experiencia no se hace, sino que se padece. (pp. 17-18)

Al respecto se aprecia que desde varias líneas conceptuales la cuestión personal o profesional de transcurrir en los tiempos, en una trama de relaciones, en contextos sociopolíticos determinados, dejan marcas, indicio certero de que la experiencia se padece.

A estas cuestiones se suma, en este caso, la particularidad de la experiencia de estar en la institución ocupando cargos jerárquicos. "Que me iba a imaginar mirá: rectora del... (Instituto de formación docente de mayores dimensiones). Vos decís cómo va a llevar al Instituto con la rectoría... nunca...." Realmente se presenta como un desafío el desempeño de cargos de alta jerarquía, y aparentemente hay un dejo de inseguridad o de falta de certeza respecto de cómo llevar adelante la función y la institución, y a la vez también hay una suerte de presagio, sentimientos que se traducen en la expresión "cómo va a llevar al instituto... nunca". Toulmin (1977) sostiene "vale la pena luchar por los roles, cargos y posiciones de influencia de una profesión científica..." (pp. 272-273). Coincidentemente la docente manifiesta: "Y cuesta hacer tantas cosas mirá... llegar a los cargos y después poder haber trabajado en estos cambios curriculares, los diseños..." En relación con estas cuestiones, puede notarse que en esa lucha por los cargos pueden realizarse ciertas actividades quizá más prestigiosas o significativas que rejerarquizan las posiciones de influencia.

No obstante, esta lucha por ocupar o mantener cargos de cierta influencia, las presiones son continuas y fuertes por lo cual, aparentemente, la docente se ve superada, desbordada por las situaciones que se viven en el ámbito profesional y opta 
por dejar estos cargos y o espacios por los cuales ha luchado, lo cual se advierte nítidamente en la expresión "todas esas cuestiones que te superan".

En el abandono de estas posiciones se vislumbran razones personales, "dejé la rectoría y la vicerrectoría, por razones personales. Decidí por mí, dedicarme un poco más de tiempo a mí". Las razones que justifican acciones anteriores, por ejemplo "dejar la rectoría..." deben hacer referencia a un pretérito, a un tiempo anterior y hechos que motivaron la acción. Sin embargo, para el caso, se hace referencia a razones orientadas hacia el futuro, más bien proyectos de acción que ideas causales. A tal efecto destacamos que dice "por razones personales. Decidí por mí, dedicarme un poco más de tiempo a mí". ¿Acaso el tiempo para sí misma no fue suficiente en este período?

La significatividad motivacional libre refiere a la cadena de motivaciones determinada por el proyecto de acción futura; la significatividad motivacional condicionada es la "actitud biográfica" determinada por motivos sedimentados. ¿Por qué no aparecen motivos porque y si expresa motivos para? Los motivos sedimentados ¿pudieron haber sido cadenas de incidentes críticos negativos que es preferible no transparentarlos sino más bien generar nuevas proyecciones a partir de ellos?, y entonces, ¿por qué no saldar deudas referidas a aspectos personales, "dedicarme... a mí"?

Siguiendo con las decisiones relacionadas con el ordenamiento social, centramos nuestra mirada ahora en las cuestiones familiares que cobran un peso decisivo al establecer prioridades. ¿Cómo es posible la vinculación de estas cuestiones con la vida profesional? "La historia intelectual de una profesión, la historia institucional de esa profesión y las biografías individuales de los hombres se tocan, interactúan y se funden" (Toulmin, 197, p.311). En esta intersección se pueden apreciar prioridades en función de coordenadas temporales del mundo cotidiano que tiene un curso fijo a la vez que muestra nuestra finitud y se impone a nuestros proyectos, lo que implica el establecimiento de prioridades.

Al respecto la entrevistada expresa: "Dejé varias cosas. Ahí corté con el nivel secundario porque justo hubo concursos y no pude participar por problemas familiares...establecí prioridades y fueron por razones justamente familiares, que ahí yo perdí varias cosas." Las ideas "corté, perdí, dejé" representan algo que ha quedado en otro momento, algo que se desvincula de la vida, evidenciando que el tiempo es irreversible, no se puede volver atrás; afecta la historia y la de los demás. Esto condiciona las expectativas y los proyectos, los cuales deben ordenarse según las preferencias, los intereses, los deseos, las premuras: lo primero, lo indispensable, la significatividad de las situaciones.

\section{En directa relación con el ordenamiento temporal}

Se puede captar desde el curriculum vitae esta cuestión de "dejar varias cosas", lo que se visualiza en un avance y ascenso en niveles y funciones, hasta un momento en que ese movimiento hacia delante se detiene y se produce un regreso hacia cargos y funciones anteriores. Esto se corrobora en la entrevista con el comentario: "dejé la rectoría y volví a la coordinación". Esto lleva a reflexionar e indagar respecto de motivaciones, razones, intereses que en el apartado anterior se ampliaron. 
Asimismo, desde el documento mencionado se interpreta que se dan períodos de aceleramiento y acumulación de actividades en general, pero también se da un quiebre, una disminución de estas actividades durante un período intermedio, que dura aproximadamente tres años. Esto es coincidente con la expresión de la docente: "no pude participar por problemas familiares...establecí prioridades y fueron por razones justamente familiares, que ahí yo perdí varias cosas".

Otra cuestión que se aprecia en el documento y que hace a lo temporal, es el enfoque que le fue dando a su formación, mostrando una amplitud y variedad de actividades y recorridos (secundaria, coro, pintura, entre otros) para ir especificando actividades y concretando un trayecto en la formación docente, nivel superior no universitario y universitario.

El contacto relativamente "tardío" con Instituciones universitarias movilizó también las posibilidades de indagación respecto de los tiempos en su vida profesional, y la voz de la docente da indicadores para comprender el movimiento de su trayectoria, como ya se señalará.

En el análisis las perspectivas temporales de ahora y entonces, antes y después, pronto o tan pronto, se articulan sobre la ubicación temporal... el ahora actual es el origen de todas las perspectivas temporales según las cuales se organizan los sucesos dentro del mundo. Retomamos en primer lugar acciones que se dieron en un antes y que acentúa en su relato la docente: "En el XX (se refiere a un lugar de trabajo), hay una historia detrás y en XX no hay nada, encima nunca me conocieron" (el destacado es personal).

El "detrás" hace referencia a retrospección, a experiencias vividas, a una biografía que se desarrolló en un espacio determinado y en un tiempo anterior; mientras que el "nunca" implica también un tiempo anterior al "ahora", respecto de un vínculo que no existió y que, por tanto, no se hace presente a la experiencia actual, al ahora.

Podemos advertir, desde la voz de la entrevistada, una mirada del aquí y ahora, pero "que se remite a distintos pasados que intentan dar cuenta de los recorridos seguidos que llevan al lugar en el cual cada uno se narra en este aquí y ahora" (Nicastro y Greco, 2009, p.28). Valoramos entonces la historicidad como proceso, la trayectoria en el interjuego del tiempo.

Este ordenamiento temporal también se señala en relación con lo espacial, necesariamente vinculados: "Hubo un tiempo en que pedí licencia durante seis meses en rectoría, fue cuando tuve dificultades y me alejé un poco de la institución. Tomé distancia antes de tomar la decisión de renunciar a la rectoría". En este sentido, se puede advertir un tiempo, un antes en la búsqueda de distancia para encontrar "material interpretativamente significativo adicional" (Schutz, 1973, p. 209), lo que insinúa que las decisiones profesionales implican procesos de evolución que requieren necesariamente tiempo y en los cuales se imbrican, además, diferentes factores, tales como los que se fueron citando en los ordenamientos anteriores. Cobra importancia aquí la segmentación del tiempo y la espera, lo que demuestra la independencia del tiempo del mundo natural y el tiempo subjetivo.

Se hace imprescindible destacar en este apartado del análisis el particular ordenamiento de los tiempos en las Instituciones escolares, mediante cronogramas 
que indican períodos escolares y épocas de recesos, a fin de explicitar el contexto en el cual surgen y se insertan las manifestaciones del relato. Decir "el 15 de Enero"(enfatizado) es decir "volví en pleno receso de verano, en plena licencia anual", y si a esto, además, le adicionamos el factor causal: "porque me llamaron del Ministerio para decirme que abra el Instituto de 6,30 a 12 hs. para colocar alarmas", esto demuestra que se interrumpieron las vacaciones por indicaciones de un superior jerárquico, y en función del contexto administrativo, político y social que imperaba en ese momento, en el cual había necesidad aparente de instalar alarmas. En la entrevista expresa "15 de enero" sin aclaración alguna, porque desde su situación biográfica particular, y obviamente desde la situación biográfica del entrevistador, docente también, esto es una obviedad, esto es una categoría temporal que ya opera de un modo especial en los profesionales docentes de esta región geográfica.

En esta situación, cabe la expresión "me harté y dije: hasta acá llego, ya tenía decidido renunciar". Se entiende que los sucesos acontecidos actuaron como detonantes para definir situaciones profesionales que estaban siendo deliberadas; este hecho actuó como acontecimiento en el sentido de "asistir a una experiencia que nos ocurre, que se apodera de nosotros, que nos tumba y nos transforma. El acontecimiento es lo 'grave' [...] aquello que da a pensar y rompe la continuidad del tiempo: un antes y un después” (Bárcena y Melich, 2014, p.172).

Podemos señalar, siguiendo ideas de Woods (1997) que se presentó un incidente crítico (tal vez uno más a la cadena que no se mencionó explícitamente) y que aportó a la definición de un giro en la trayectoria profesional. Aparentemente se dieron:

...momentos y episodios muy cargados que tienen enormes consecuencias para el cambio y desarrollo personal. Episodios que no están planificados, ni anticipados, ni controlados, (...) fogonazos que iluminan en un momento electrizante algún aspecto problemático clave 0 aspectos del papel del profesor, y que contienen, en el mismo instante, la solución. (p. 18)

Continuando con la dimensión temporal vale señalar los procesos de reflexión respecto de la carrera, captándose la docente en sus actos pasados.

El mismo acto de reflexionar es posible únicamente si el objeto sobre el cual se reflexiona forma parte del pasado, aunque este sea el pasado inmediato [...] la autoconciencia no puede ser captada sino en tiempo pasado. (Natanson, 1974, pp. 20-21).

En esta dirección, la docente expresa varias veces un replanteo de su labor: "yo me ponía a pensar, trabajamos, nos forman supuestamente para profesores y yo doy psicología y no se enseñar psicología a estos adolescentes"; "hasta hoy tengo dudas acerca de cómo enseñaba..."; "creo que buena carrera hice. Yo estoy contenta con mi carrera". Estas expresiones vislumbran que en el devenir del tiempo puede captarse la acción ya realizada y comprender que en la vida pueden darse respuestas de diferente grado en relación con el éxito y la desilusión.

En este sentido, dice Natanson:

...todo acto de reflexión involucra una distancia entre el que reflexiona y aquello sobre lo cual reflexiona... cuando reflexiono sobre mí mismo... sólo 
puedo ocuparme de mi como objeto para la reflexión, lo cual significa que siempre capto una fase anterior a mí. (1974, p. 26)

Hernández Hernández, Sancho Gil, Hermosilla, Martínez Pérez y Creus (2014) vinculan la reflexión sobre la propia subjetividad, sobre el lugar que se ocupa y el que se quiere ocupar con la de la identidad docente. En este sentido esta profesora reflexiona sobre los avatares de la docencia, de los cargos, de la política, y define su elección hacia la tarea y función antes desempeñada. Una cita de los autores ilustra exactamente estas opciones:

(la identidad) se convierte en una opción que cobra un sentido especial entre aquellos que asumen su tarea no desde una posición funcionarial, como una forma cualquiera de ganarse la vida, sino desde la capacidad de ser con los otros y desde la disponibilidad para cambiar. Porque así cobra sentido no solo el papel que se ocupa, sino la relación que de sí mismo se construye con los otros. (2014, p. 106)

Cerrando este análisis podemos comentar que el entrecruzamiento de elementos tan importantes y sentidos para comprender una trayectoria profesional, la trama misma del desarrollo profesional, sus vaivenes, aceleramientos y desaceleramientos, sentimientos, fases, motivos retrospectivos y prospectivos no pueden captarse en un currículo escrito sino en la dinámica misma de la profesión y a través de unos componentes centrales, fundamentales, tales como son la memoria y la voz de los actores.

\section{Conclusiones}

Las conclusiones giran, en principio, en torno a la posibilidad de describir el trayecto profesional de un docente, a partir de las cuestiones que surgen del análisis mismo del currículo vital. En este sentido, puede afirmarse que un currículum vitae como documento escrito, puede mostrar diferentes actividades de una persona en un ordenamiento espacial y temporal determinado, por tanto, pueden verse "movimientos" por diferentes ámbitos de trabajo en el devenir del tiempo, pero nada dice ese documento respecto del ordenamiento social.

Se puede asegurar que se advierten períodos o etapas en diferentes niveles y funciones, se advierten, además, períodos de aceleramiento y condensación de actividades que hace pensar en una intensificación laboral y así también se puede ver en qué momento, el camino se presenta pautado, lento, sereno.

En cuanto a la interpretación de decisiones tomadas y las alternativas vislumbradas se recurre a la voz de la docente y se concluye que cabe destacar la importancia de "terceras" personas que inciden en las decisiones respecto de la elección de la carrera profesional. Por ello se enfatiza en el análisis la perspectiva del ordenamiento social, afianzada en los motivos familiares y contextuales políticos y económicos que, con fuerza, inciden en el recorrido trazado.

Por otro lado, la concepción de espacio resulta crucial también al decidir la carrera, en virtud de pretender espacios plenos de "decoro", orden y limpieza, cargados de ideología cristiana, aunque fueran de nivel terciario, en contraposición de ambientes más desestructurados del ámbito universitario, carentes de formación religiosa. En este ámbito de lo espacial, no se puede dejar de lado la necesidad de proximidad con las personas, del vínculo "cara a cara" y de necesidad de cursar una 
carrera de complementación con la condición de que hubiera clases estructuradas en un aula y tiempo determinados. Todas estas cuestiones influyeron a la hora de tomar decisiones.

Merece un punto y aparte la importancia ejercida por las presiones políticas y sociales en tiempos de ocupar cargos jerárquicos, siendo detonantes de renuncias en el desempeño profesional.

En función del análisis realizado, se considera pertinente cerrar este trabajo afirmando "el mundo cotidiano de la acción es el presupuesto que, como bucle recursivo, entrama todos los demás estratos de la realidad humana" (García de Ceretto, 2007, p. 45). Desde esta perspectiva, resulta interesante abordar la trayectoria profesional vinculada al ciclo vital de una persona, al curso de acción que cada sujeto emprende configurando así su recorrido profesional, situándose en la vida de una manera específica a la luz de su situación biográfica. En tal sentido, la vida profesional y la historia personal, se articulan, se entraman, de manera inusitada. Vale la pena ahondar en estas relaciones.

\section{Referencias bibliográficas}

Bárcena, F. y Melich, J. (2014). La educación como acontecimiento ético. Natalidad, narración y hospitalidad. Buenos Aires, Argentina: Miño y Dávila.

Gallart, M. A. (1992). La integración de métodos y la metodología cualitativa. Una reflexión desde la práctica de la investigación. En H. Forni, M. A. Gallart \& I. Vasilachis de Gialdino. Métodos cualitativos II. La práctica de la investigación. (pp.107-151). Buenos Aires, Argentina: Centro Editor de América Latina.

García de Ceretto, J. (2007). El conocimiento y el currículum en la escuela. El reto de la complejidad. Rosario, Argentina: Homo Sapiens.

Goodson, I. (2003). Hacia un desarrollo de las historias personales y profesionales de los docentes. En Revista Mexicana de Investigación Educativa, 8(19), 733- 753.

Hernández Hernández, F., Sancho Gil, J., Hermosilla, P., Martínez Pérez, S. y Creus, A. (2014). Tránsitos identitarios de docentes desde las historias de vida. En Rivas Flores, J., Leite Méndez, A. y Prados Mejías, M. (Coord.). Profesorado, escuela y diversidad. Málaga, España: Aljibe.

Jackson, P. (2005). Sobre el lugar de la narrativa en la enseñanza. En H. McEwan \& K. Egan (Comps.). La narrativa en la enseñanza, el aprendizaje y la investigación. Buenos Aires, Argentina: Amorrortu.

Larrosa, J. (2014). Experiencia y alteridad en educación. En C. Skliar y J. Larrosa (Comps.). Experiencia y alteridad en educación (pp.13-44). Rosario, Argentina: Homo Sapiens.

Leite Méndez, A. y Rivas Flores, J. (2014). La dimensión perdida. La construcción política de la identidad docente. En J. Rivas Flores, A. Leite Méndez y M. Prados Mejías (Coords.). Profesorado, escuela y diversidad. Málaga, España: Aljibe. 
Moreno Olmedilla, J. (1998). Notas para una genealogía de los estudios curriculares en España. Profesorado: Revista de curriculum y formación del profesorado, 2(2), 11-30. Recuperado de https://dialnet.unirioja.es/servlet/articulo?codigo $=195346$

Natanson, M. (1974). Introducción. En A. Schütz, El problema de la realidad social. Escritos I (pp.15-32). Buenos Aires, Argentina: Amorrortu.

Nicastro, S. y Greco, M. (2009). Entre trayectorias. Escenas y pensamientos en espacios de formación. Rosario, Argentina: Homo Sapiens.

Salinas, D. (1995). Currículum, racionalidad y discurso didáctico. En M. Poggi (Comp.). Apuntes y aportes para la gestión curricular (pp. 21-59). Buenos Aires, Argentina: Kapelusz.

Schutz, A. \& Luckmann, T. (1973). Las estructuras del mundo de la vida. Buenos Aires, Argentina: Amorrortu.

Toulmin, S. (1977). La evolución de los conceptos. Madrid, España: Alianza.

Woods, P. (1997). Experiencias críticas en la enseñanza y el aprendizaje. Buenos Aires, Argentina: Paidós. 